\section{Disaster strikes from the blue}

\section{Peter J. Smith}

Earthshock. By Basil Booth and Frank Fitch. Pp. 257. (Dent: London, Toronto and Melbourne; Walker: New York, 1979.) Hardhack £6.9.5, \$11.9.5; paperback available from Sphere (London) in May, 1980.

Wirhin ten minutes of taking up this book I had come to two conclusions, both minor in themselves but both, it subsequently hecame clear, indicative of deeper malaise. The first was that somcone has seen fit to impose a veneer of silly sensationalism on an already spectacular topic, presumably in the belief that a bit of spurious exaggeration does little harm to sales. It begins with the titie. An earthshock, it seems, is simply a natural disaster. A short snappy title is all very well, and even to be applauded, but not at the expense of accuracy. As not all natural disasters (for example, glaciation) can be remotely regarded as "shocks", the authors are reduced to referring to "slow earthshocks", which reminds me of that superb character of childhood rhyme, the "hare-footed man with clogs on [who] came slowly running past".

Then there is the lurid dust jacket, showing a huge "tidal wave" about to overwhelm a Manhattan-style environment. Well, all right. More importantly, however, there is the jacket blurb which asks, "can the Earth survive?" and asserts that "A single great natural disaster... could destroy civilisation as we know it". For a start, no-one outside Monty Python refers any more to "civilisation as we know it", at least not without inviting ridicule. Yet the hasic fault here is not some blurb-writer's exuberance but the authors, who adopt the same tone in parts of the text. They begin the book, for example, with a crude fivepage account of the destruction (in 1987) of America's eastern seaboard by a fireball and its aftermath, and subsequently discuss nation-scale disaster from a serious scientific point of view. Is it worth spending time thinking about such unlikely (hut admittedly possible) catastrophes when we cannot even cope adequately with events that are more familiar?

The second conclusion is that the book contains far too many flowstoppers, ranging from the trivial to the more serious. The Earth's crust, mantle and core are referred to throughout somewhat eccentrically as
Crust, Mantle and Core. "Dilatancy" has become "dilatency". "Pangaea" appears as "Pangea"-a perfectly acceptable, indeed desirable, simplification in the context of the abolition of all ligatured diphthongs and their remnants, but presumably a mistake in a book that refers to aeolian, Palaeozoic and palaeomagnetism (and even, in one place, the idiosyncratic "palaeomagnetic"). Imperial units (feet, miles, and so on) are used throughout without even the parenthetical acknowledgement of metric units-a disgrace when (outside North America) a whole generation of children has been brought up on metric units. And even more seriously, one is continually being brought up sharply by the almost impenetrable: "However academic the study of plate movement may seem, its importance cannot be minimised". What does this mean? - the very opposite of what it actually says?

If that were the sole extent of the problem I could perhaps be accused of nit-picking. Unfortunately, however, the confusion goes much deeper, ruining some good ideas in the process. For example, before tackling natural disasters as such, Booth and Fitch devote some 50 or so pages to spelling out the nature of the generally more gradual processes involved in the Harth's behaviour. This is an excellent approach. All too often the authors of "popular" hooks on natural hazards give the impression that disaster strikes from the blue with little, if any, reference to the context in which terrestrial events and processes can combine to produce catastrophe. But to cover this hackground in so short a space is difficult and needs careful planning. Booth and Fitch do not entirely succeed. This section is rather confused, dense in concepts and terms all too frequently inadequately explained, and thus likely to be hard going for the non-expert.

The remainder of the book is devoted largely to particulat natural hazards-to their general characteristics and to specific examples of disasters they have generated. Here the going is easier. To me, these chapters hecome more and more engrossing as the material becomes less and less familiar during the progression from earthquakes, through volcanoes, glaciation and flooding to extraterrestrial bombardment. But individual readers will have their own interests. To be objective about it, the book is probably most authoritative on those topicsespecially volcanic matters--closest to the authors' hearts. On subjects closer to my heart. on the other hand, respect for the facts is not always all it should be. The notorious Denver earthquakes of the 1960s were not noticed by US
Geological Survey scientists in 1966 but by the alarmed inhabitants of Denver some years before; and the cause of the shocks was discovered by David Evans, a consultant geologist, in 1965. Moreover, the cause was not the injection into the ground of "industrial" waste fluids but of military waste material. The emotional overtones of the affair were thus rather different.

Some of the authors' judgements are also questionable. To say, as Booth and Fitch do, that "If the scientists involved in this work [that is, earthquake studies] are given sufficient encouragement and adequate financial support there is no reason why earthquake prediction should not become a routine matter within a decade" is really far too optimistic and therefore grossly misleading to the uninitiated. Indeed, it seems an unlikely prognosis even in respect of geologically comparatively simple areas such as the San Andreas fault zone of California. Moreover, to give the impression that prediction is purely or even primarily a scientific problem is dangerous. The social implications of a viable earth. quake prediction capability are so complex that there must be real doubt whether non-totalitarian régimes could cope adequately with such a power without significant, and perhaps unacceptable, changes in socio-political attitudes.

Failure to give adequate attention to such factors is to demonstrate political naivety, a condition not uncommon among academic scientists. It is also naive to suggest, as Booth and Fitch do, that "the United Nations should have a single, comprehensive world natural disaster control agency with certain overriding powers, able to investigate and prepare for all types of natural disaster anywhere in the world, ready to go in with the right kind of advice and aid immediately it is required, without political let or hindrance". The United Nations has been conspiculously unsuccessful in almost everything it has ever tried to do precisely because such supranational authority is totally unacceptable to any nation of any consequence; and perhaps there is some merit in that uncooperative attitude when one takes account of the motives of the supranationalists. As Booth and Fitch put it. "people must be prevented from falling victim to their own or other people's stupidity and avarice by strictly enforced laws". Nasty.

Despite its descriptive merits, the long-awaited Earthshock is at best a disappointment and at worst a bit of a disaster.

Peter J. Smith is Reader in Earth Sciences at the Open University. Milton Keynes. UK. 